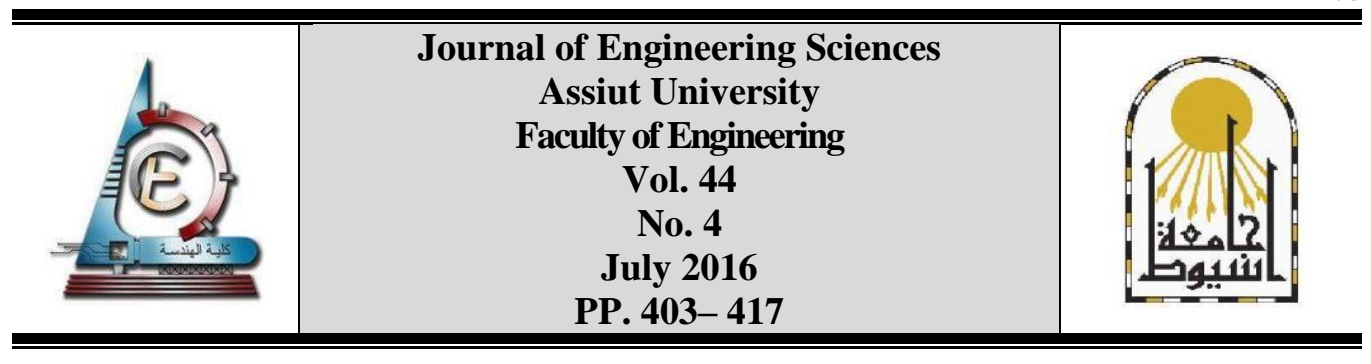

\title{
A STUDY OF EQUITABLE ACCESSIBILITY AND PASSENGERS FLOW IN FUTURE STATIONS OF CAIRO METRO
}

\author{
S. H. ELDAKDOKY \\ Department of Architectural, Faculty of Engineering - Helwan University, Cairo, Egypt \\ Received 5 May 2016; Accepted 30 May 2016
}

\begin{abstract}
This work aims to solve the issues of equitable accessibility, and passenger comfort in future Cairo metro stations at micro-level during normal operation. First, the conventional evaluating tool for capacity of station facilities, and the design considerations for passengers flow in rail transit stations were recalled. Second, three future stations with different characteristics were selected as samples of study; the relevant data were collected from Tender documents. The accessibility of stations was analyzed using an access checklist extracted from disability code. Then, Flow-density analysis inside ticket hall of each station was carried out using micro-simulation software. The results showed that the stations accessibility does not achieve needs of passengers with disabilities. Moreover, levels of service inside the ticket halls are very poor and uncomfortable, although the capacities of passengers' facilities were calculated according to NFPA restrictions. Right angle junctions, service facilities existing in cross-flow, and reverse flow directions are the factors that create congestion zones and reduce the level of service. The study concluded that concept of accessibility for disables should be given more attention, whereas applying the spatial separation concept between passengers boarding and alighting will reduce the flow density and optimize the level of service.
\end{abstract}

Keywords: Transit Stations; Passengers; Equitable Accessibilities; Flow Density.

\section{Introduction}

Rapid transit system is an electric transportation system that operates on right of way for heavy passengers' movement within major metropolitan areas [1]. It gives a higher level of service in comparison to other public transportation modes. However, the congestion that creates unsafe and uncomfortable conditions in transit stations reduces the desirability of transit for probable passengers [2]. Passengers' flow is the number of passengers that go through a cross-section of a space during a defined period [2], which is influenced by number of passengers and spatial design of this space. Hence, well design of transit station is capable of alleviating congestion, increasing stations capacity, and enhancing passenger safety [3]. The most relevant standards for design of transit stations are :(1) the Standard for fixed guide way transit systems (National Fire Protection Association, NFPA 130) that focuses on enabling safe evacuations during peak conditions and determines the minimum capacity of station elements based on precise evacuation time [1], and (2) Egyptian disability code [4] and standard for Americans with Disabilities Act (ADA) [5], which focus on the needs of persons with disabilities. Pedestrian flow formulas 
were developed from the relationship between density and speeds of pedestrian, as shown in Fig.1 [6]. According to numbers of passengers in peak hour and these formulas, dimensional requirements for transit stations facilities can be easily calculated using spreadsheet [1]. This conventional tool aims to achieve the passenger's safety regardless of their comfort. So this tool might be insufficient in complex stations due to the design issues that are not accounted for in NFPA [3]. Currently, microscopic pedestrian flow simulation model that exists in various forms and features is utilized to give virtual traffic very close to reality [7]. For instance, VISSIM [8], Legion and Any Logic are software packages give an efficient level of pedestrian flow analysis.

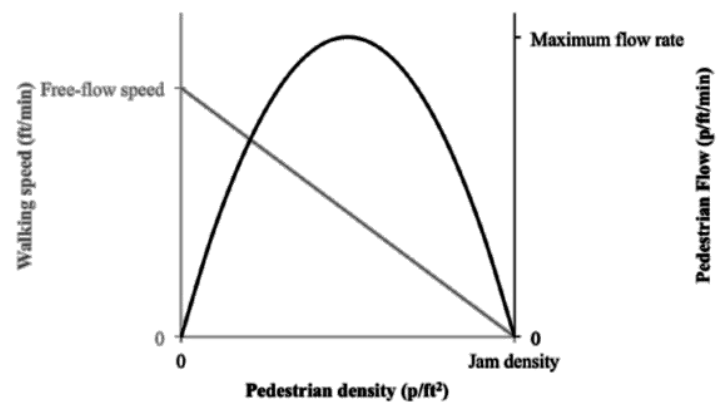

Fig. 1. Relationship between density, speed, and flow of pedestrian [6]

Metro network has about 30 years in Egypt. It was mainly planned to optimize inhabitants' mobility and to reduce the number of car-dependent [9]. Currently, this network comprises of two complete lines and third line under partial operation and construction. This third line is almost $43.5 \mathrm{Km}$ serving 33 Stations, and runs east-west from Cairo Airport to Imbaba. It is divided into four phases; the first two phases consist of $12 \mathrm{Km}$ serving 9 stations, and are in operation since 2011\&2013. The other two phases are currently under study. The numbers of daily passengers are continuously growing due to the extension of this network [10], which will badly increase the congestion in the future stations as well as in many of the existing stations. Though, neither architectural design concept nor evaluating tool of the future stations of Cairo third line is updated for mitigating this issue. Moreover, the accessibility of persons with disabilities to these stations is not fairly considered as well. Therefore, this work aims to evaluate and improve the equitable accessibility and passenger comfort, in the future stations of Cairo metro third line at micro-level. For this purpose, the work is mainly divided into theoretical part and analytical part. The first part highlights design considerations for equitable accessibility and comfortable flow in metro stations. The analytical part evaluates the accessibility performance of the examined stations based on a checklist extracted from the disables requirements, and the flow-density based on simulation software technique. Based on results, improvement modifications are proposed and explored.

\subsection{Related work}

Pedestrians' flow analysis within buildings has attracted there searchers in the recent years. For instance, rapid walking behavior was studied for two cases of flow directions in right angle junction. The first case consisted of two straight ways of pedestrians' inflows which are combined at 90 degree. The second case consisted of two perpendicular ways of pedestrians' inflows which are combined in straight way. The results clarified that pedestrians reduced their walking speed with elapsing of time in order to not confect with 
each other. Moreover, pedestrians' inflow in the first case was more efficient by $51 \%$ than the second case. The study concluded that the flow direction is significantly effective for crowd control in high occupancies public spaces [11].

Recently, pedestrian flow modeling attracts the community of transportation research to show pedestrians movement within spaces, and to study safety and transportation facilities incorporation. Research of "modeling pedestrian circulation in rail transit stations using Micro-Simulation" explained the potential procedures for analyzing pedestrian flow in rail transit stations utilizing micro-simulation. It clarified the static and dynamic data required for model simulation, and criteria of model calibration. VISSIM software was used for exploring the suggested operational and infrastructure modifications in the North Melbourne Rail Station. The study gave a good example for the potential application of micro-simulation technique in pedestrian movement analysis [12]. Moreover, research of "Scenario analysis of pedestrian flow in Public Spaces reviewed pedestrian modeling literatures to highlight this domain. An actual pedestrian simulation was carried out in a entrance hall of the SV building at Ecole Polytechnique Fédérale de Lausanne using VISSIM software. Two cameras were fixed in this hall to collect the data required for model validating. Then, the study proposed enhancement scenario in which one access door was selected exclusively for entry and the other one for exit. The results clarified more fluent flow at and less travel times. The work concluded that methodology of this work can be applied in other simulation schemes [13].

On the importance of suitable accessibility for vulnerable groups in Metro systems, the accessibility to the mass rapid transport systems in Bangkok Metropolitan Region was evaluated. The study created multi-dimensional assessment criteria to explore how various groups of users have accessed to the systems. In the light of the abilities and needs of disabled and elderly, it was found that accessibility of the system is not well. The study highlighted that accessibility assessment should consider different accessibility aspects. It also proposed that policy actions could be useful for providing safe access for passengers and suitable feeder services [14].

\section{Method}

For achieving the purpose of this work, the designing considerations for equitable accessibility and comfortable flow of passengers in rail transit stations was firstly highlighted. Then, three stations were selected as applied samples. The selection criteria were: passengers' density, type of the station, location of the station on the entire line and architectural design diversity. The relevant data were collected from the Basic Design documents for phase 3 of the third line. The architectural features of the examined stations were explained. Accessibility Performance at Micro-level was first analyzed and evaluated based on an access checklist extracted from the requirements of Egyptian disability code [4] and ADA standard [5] that includes more comprehensive items. Then, analysis of flowdensity was carried out in ticket halls of the examined stations only; this selection is justified because the main functional areas is housed in ticket hall, and the most interactions between passengers takes place in this open space as well. Anylogic simulation software was utilized to simulate the passengers' movement at peak time during normal operation. To validate Any logic model outputs, passengers' density in ticket hall of existing station (Cairo fair station) was simulated. In the same time, it was also monitored in reality for $1 \mathrm{hr}$ at four positions; the results obtained using simulation were compared with that obtained from field monitoring, Fig. 2. It can be noted that the difference between them is less than $10 \%$, which an acceptable accuracy. 


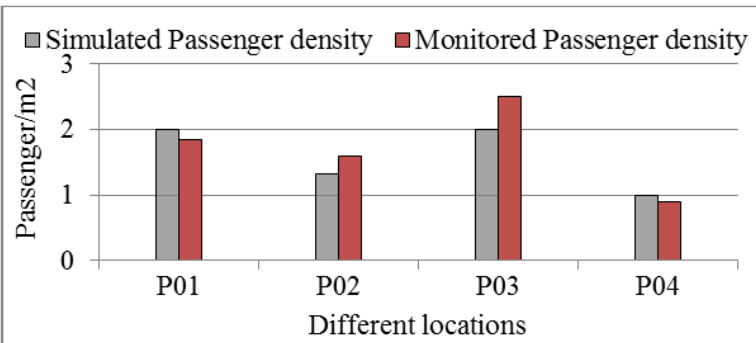

Fig. 2. Comparison between passengers' density resulting from simulation and monitoring in ticket hall of Cairo fair station

Capacities and locations of passengers' facilities, an number of boarding and alighting passengers were simulated based on the data mentioned in the functional studies of stations [10]. To evaluate the level of service in each hall, the flow density resulted from simulation were compared to flow density of the defined six categories (A-F) for service level in horizontal walks and waiting area [15]. Based on the results, the defects were specified. Consequently, proposals for improving the passenger comfort in the stations were suggested and explored using Any logic.

\section{Designing considerations for equitable accessibility and comfortable flow}

All stations are functionally designed to provide platforms and a ticket hall that includes ticket offices, turnstiles, obstacle-free circulation routes, vertical circulation facilities, entries and exits [16]. The design should fulfill several aspects such as well accessibility, safety, and comfort for all passengers regardless of ability or age. Passengers in transit stations experience almost the same sequence of procedures, as shown in Fig. 3 [2].

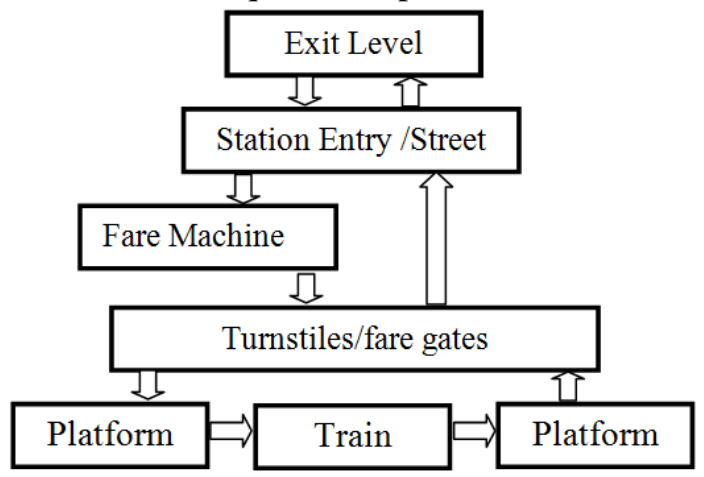

Fig. 3. Diagram of transit station passenger flow [2]

Internal arrangement of all stations should consider the following principles [4] [5][11][16]:

- Equitable use for passengers with different abilities.

- Arranging circulation routes and facilities to be easy, safe and direct.

- Minimizing passengers' congestion and travel distances, as well as avoiding deadend conditions as much as possible.

- Calculating the dimensional requirements for all station elements based on the expected number of passengers during peak hour.

- Considering the behavioral and physical characteristics of passengers such as walking side, walking speed, age distribution, disabilities, and social distance.

- Identifying circulation routes and service facilities by efficient signage. 
- Achieving at least one accessible route for disables and elderly, and providing the platforms with warning lines for visually impaired passengers.

- Carefully considering flow direction through bottleneck that might be result from complex architectural arrangements, as small crowd movement zone in a circulation route could cause a great change in terms of evacuation process.

- Avoiding both of passengers' cross-flow and passengers' flow moving in the opposite direction as much as possible.

- Distributing entries and exits evenly to reduce congestion.

- Providing queuing space around the ticket offices, turnstiles, elevator, stairs and escalators to avoid undue congestion.

\section{Selection criteria of stations for study}

The newest phase of the third line, phase 3 , is almost $17.7 \mathrm{~km}$ length serving 15 stations. These stations are divided into eight underground stations, two at grade stations and five elevated stations as shown in Fig. 4. The route starts underground at Attaba area and extends under 26 July St., it crosses the two branches of Nile and runs under Zamalek district. Then, the route is divided into two sections: The northern section that runs under Sudan Street till Rod El Farag corridor, and the southern section that starts under Ahmed Orabi St. to end at Cairo University station in Boulak El Dakrour. Three of these stations were selected, as shown in table 1, for the study. The selection criteria of the stations are as the followings:

\section{Table 1.}

The selected stations as samples of applied.

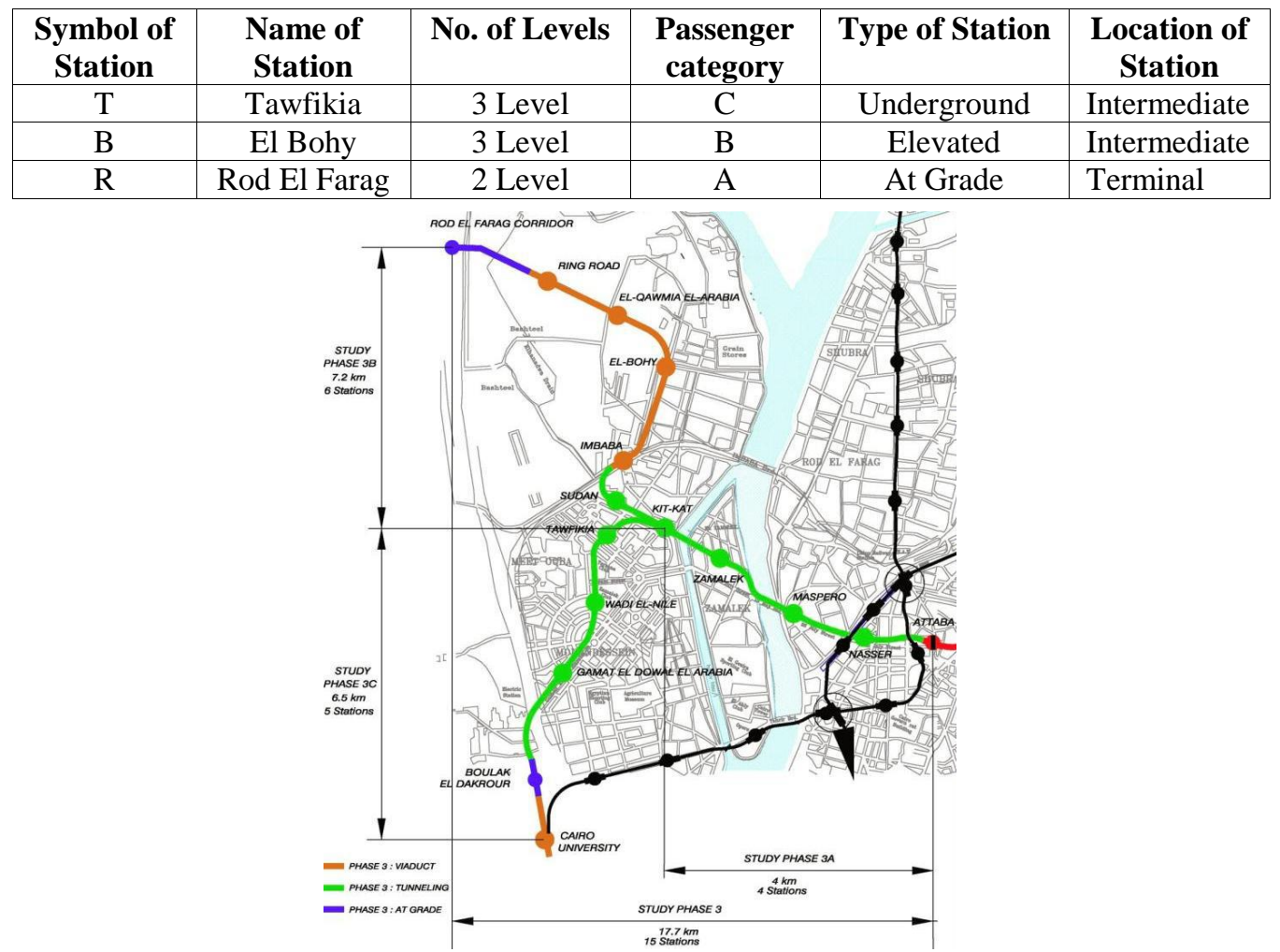

Fig. 4. Phase 3 of the third line 


\subsubsection{Passengers density}

Passenger density in Cairo transit stations are generally classified into three classes (A, $\mathrm{B} \& \mathrm{C}$ ). Class $\mathrm{A}$ is the most congested class that includes more than 30.000 passenger $/ \mathrm{hr}$, whereas class $\mathrm{C}$ includes the least number of passengers, less than 15.000 passenger $/ \mathrm{hr}$. Phase 3 included five stations of class A, nine stations of class B, and three stations of class $\mathrm{C}$ [10]. Thus, station of each class was selected.

\subsubsection{Type of the station}

Based on the alignment of the route, transit stations are classified into three types: underground station, elevated station and at grade station [17][18]. So it was considered to select one station of each type.

\subsubsection{Location of the station on the line}

Generally, transit station is classified according to its location on the line to intermediate station, intermodal station or terminal. The selected stations are two Intermediate stations and one terminal station.

\subsubsection{Architectural Design diversity}

Except the minor variations resulting from site condition of each station, Design of each type of Cairo metro stations follows one architectural concept. Thus, the selected stations give typical patterns for stations of this entire phase.

\section{Architectural description of the examined stations}

Other than the platforms in terminal station which consists of one lateral platform and one island platform, design of Platforms level in all stations is similar, which consists of two lateral platforms ( $144 \mathrm{~m}$ length) that confine two tracks. Tawfikia station is of a simple rectangle shape and consists of three underground levels. The platforms occupy the lowest underground level, $-19 \mathrm{~m}$ under pavement level, whereas the ticket hall is in the central part of the first underground level. The ticket hall as shown in Fig. 5(a)includes:(1) four entries/exits from street level, (2) two ticket offices, (3) free public hall, (4) two transversal rows of turnstiles followed by(5) two paid area and (6) two stairs groups that lead to the second underground level. The public zones in the second level are divided into two similar parts, as shown in Fig. 5(b); each part includes: (7) paid area and (8)four stairs groups leading to the platform level.

El Bohy station is of elevated type in which the tracks and platforms are integrated inside the upper level of station structure at $16 \mathrm{~m}$ above pavement level. The station occupies two over ground levels and is connected to street level by two entries. The ticket hall is divided into two similar halls located in the extremities of the first level. Each hall, as shown in Fig. 5(c), includes: (1) one stairs group running from street level, (2) Two entries/exits, (3) one ticket office, (4) free public hall, (5) transversal row of turnstiles followed by (6) paid area and (7) four stairs groups leading to the platforms in the upper level.

The terminal Rode El Farag is located at grade level, $+1.6 \mathrm{~m}$ above pavement level. The ticket hall occupies the central area, as shown in Fig. 5(d), and includes: (1) two entries/exits from pavement level, (2) three ticket offices, (3) free public hall, and (4) four rows of turnstiles followed by (5) four paid area. The two paid areas that follow the longitudinal rows of turnstiles, lead directly to departure platform, whereas the stairs groups in other two paid areas lead to the arrival platform via two footbridges. 


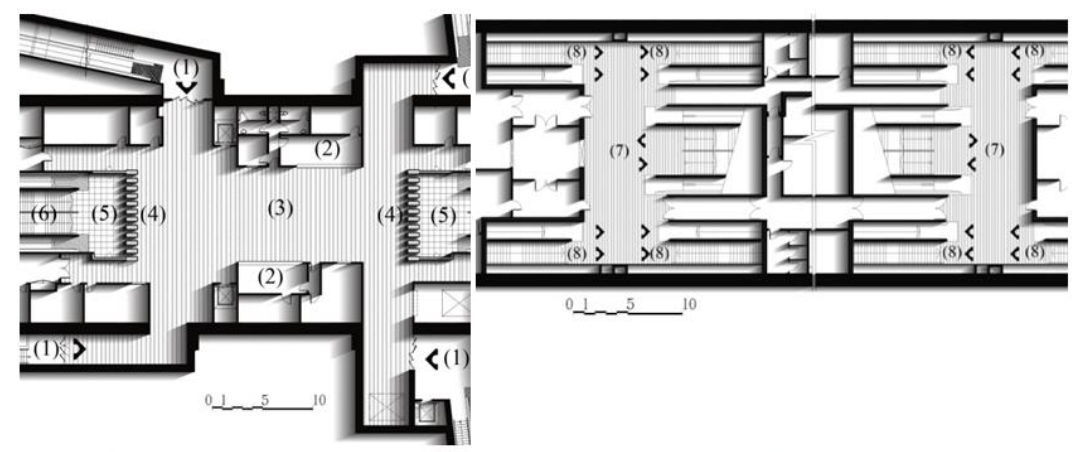

a. Ticket hall at Tawfikia station

b. Intermediate level at Tawfikia station

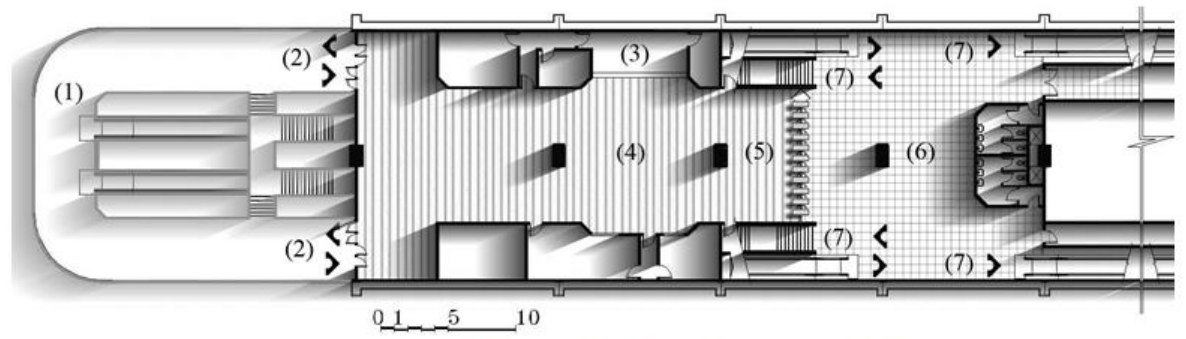

c. half plan of Ticket level (the first floor), El Bohy station

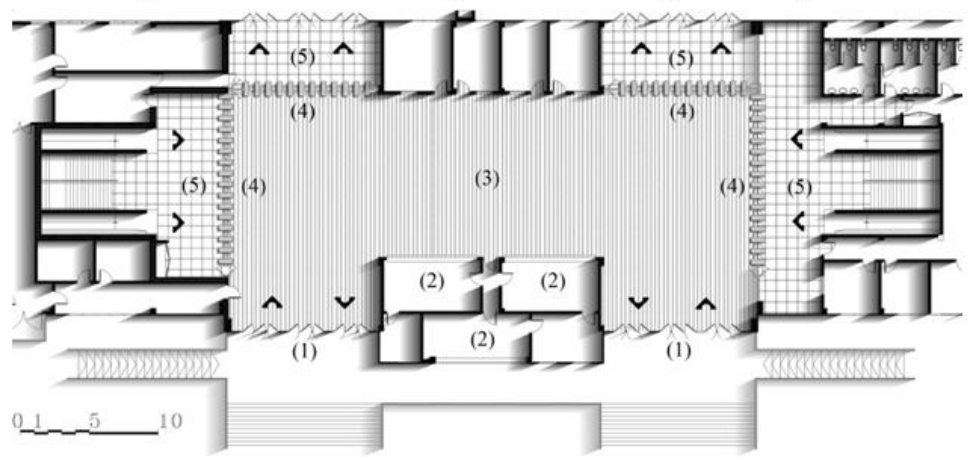

d. Ticket hall of Rod El Farag station

Fig. 5. Plans of Ticket level of the three stations [10]

\section{Evaluation of the examined stations}

\subsection{Accessibility performance at micro-level}

The following access checklist, as clarified in table 2, was prepared based on requirements of Egyptian disability code [4] and ADA Standard [5] as guidance for evaluation only.

Based on the data collected in Table 2, the available measures for disables are: elevators connecting the different levels, operable gate through turnstiles, and wide access door through entries. The other necessary requirements are not fulfilled. In other words, all stations are not equitably accessible, and passengers with disabilities will not be able to access to all stations individually without help. 
JES, Assiut University, Faculty of Engineering, Vol. 44, No. 3, May 2016, pp. 403 - 417

Table 2.

Access facilities of the examined stations

\begin{tabular}{|c|c|c|c|}
\hline Station access facilities & Tawfikia & El Bohy & Rod El Farag \\
\hline Floor finishing & \multicolumn{2}{|c|}{ Sandblasted Granite } \\
\hline Signage along the public routes & Available(Av) & $\mathrm{Av}$ & $\mathrm{Av}$ \\
\hline Escalators between different levels & $\mathrm{Av}$ & $\mathrm{Av}$ & $\mathrm{Av}$ \\
\hline Right angled junction (T-Junction) & Existing & Existing & Existing \\
\hline Mini. Width for public route & $3 \mathrm{~m}$ & $3.5 \mathrm{~m}$ & $6.7 \mathrm{~m}$ \\
\hline Elevators for disables & Available & $\mathrm{Av}$ & $\mathrm{Av}$ \\
\hline Access for disables through Turnstiles. & \multicolumn{3}{|c|}{ Av/under supervision } \\
\hline Ticket selling desk for disables & \multicolumn{3}{|c|}{ Not available(N/a) } \\
\hline Tactile information signs & $\mathrm{N} / \mathrm{a}$ & $\mathrm{N} / \mathrm{a}$ & $\mathrm{N} / \mathrm{a}$ \\
\hline Tactile warning floor & $\mathrm{N} / \mathrm{a}$ & $\mathrm{N} / \mathrm{a}$ & $\mathrm{N} / \mathrm{a}$ \\
\hline Accessible entrance for disables & $\mathrm{Av}$ & $\mathrm{Av}$ & $\mathrm{Av}$ \\
\hline Handrails for disables & $\mathrm{Av}$ & $\mathrm{Av}$ & $\mathrm{Av}$ \\
\hline treated Stairs for disables & $\mathrm{N} / \mathrm{a}$ & $\mathrm{N} / \mathrm{a}$ & $\mathrm{N} / \mathrm{a}$ \\
\hline Platforms/train horizontal gaps & $\geq 10 \mathrm{~cm}$ & $\geq 10 \mathrm{~cm}$ & $\geq 10 \mathrm{~cm}$ \\
\hline $\begin{array}{c}\text { Between car barriers, either on platforms } \\
\text { or at rail vehicles (16) }\end{array}$ & $\mathrm{N} / \mathrm{a}$ & $\mathrm{N} / \mathrm{a}$ & $\mathrm{N} / \mathrm{a}$ \\
\hline
\end{tabular}

\subsection{Flow-density in ticket hall of the examined stations}

The origin-destination for passengers entering any station is the accesses from the outside and the platforms, and vice versa. Inevitably, all passengers entering or exiting the ticket hall should pass through the turnstiles, the paid area and the stairs groups leading to platforms. Other than passengers having Discounting card, all passengers entering the station have to firstly buy a ticket from ticket office. Different setups and calculation circumstances utilized in the simulation are summarized in Table 3. Model time is determined based on the length of time that the trains take between their arrival and departure at each platform; this period shows the difficulty experienced by the passengers alighting and boarding. The logic of passengers' movement within the ticket hall is defined as a sequence of predefined routes as expected in reality. Any route can be selected on condition that the defined transitional and destination points are reached.

Table 3.

Different setups and calculation circumstances

\begin{tabular}{|c|c|c|c|}
\hline \multirow{2}{*}{ Static data } & \multicolumn{3}{|c|}{ Symbol of Station } \\
\cline { 2 - 4 } & $\mathbf{T}$ & $\mathbf{B}$ & $\mathbf{R}$ \\
\hline Ticket hall area/m $\mathrm{m}^{2}$ & 677.4 & $634.5 / \mathrm{hall}$ & 807.8 \\
\hline Free hall area/m ${ }^{2}$ & 603.3 & $373.7 / \mathrm{hall}$ & 573.1 \\
\hline No. of turnstiles & 22 & $10 /$ hall & 52 \\
\hline No. of selling points & 4 & 11 & 15 \\
\hline No. of entries/exits & 4 & 4 & 2 \\
\hline Total width of entries/exits & 13.7 & $6.8 /$ hall & 22 \\
\hline Dynamic data & 62 & 218 & 332 \\
\hline No. of Boarding passengers/min & 63 & 178 & 169 \\
\hline No. of alighting passengers/min & 2 types & 2 types & 2 types \\
\hline pedestrians grouped into types & $10 \& 6$ & $10 \& 6$ & $10 \& 6$ \\
\hline Initial speed of each type- m/sec & $15 \mathrm{~min}$ & $15 \mathrm{~min}$ & $15 \mathrm{~min}$ \\
\hline Model time- min
\end{tabular}




\subsubsection{Tawfikia station}

Flow-density analysis in the ticket hall, as indicated on Fig. 6(a), clarified that the level of service in the most zones is varied between grade $C \& D$ [15]. Though the entries experience the highest passengers-density, their level of service is grade F. In other words, the passengers in the entries will suffer from discomfort, restricted walking speeds and unstable flow. This defect results from the reverse movement of passengers through the right angled junctions of the entries. Moreover, locating of ticket office facades at cross-flow from opposite directions results in limited congestion and possible touching among passengers in this zone.

\subsubsection{El Bohy station}

As the two ticket halls of El Bohy station is typical, only one hall is simulated and analyzed. The analysis result clarified that although the station density is category B, the entries, free area, and paid area are very congested. As shown in Fig. 6(b), flow-density in these zones is varied between grade $\mathrm{E}$ and $\mathrm{F}$. Thus, passengers will suffer from serious discomfort, inevitable contact with each other, and unstable and irregular flow. This result can be justified due to the reverse movements at the entries, the location of the ticket office at cross- flow, and the existing of central columns that divide the hall and create waste area especially in paid area.

\subsubsection{Rode El Farag station}

Despite its larger area, level of service in the ticket hall is the worst in comparison to level of service in ticket halls of other stations. This result is justified due to the high volume of passengers where station category is A, and its internal arrangement. As indicated on Fig. 6(c), the area in front of the entries and the ticket offices represents bottleneck that confuses and holds up the passengers' flow, and causes probable pushing and panic. The level of service in this area is grade F. This congestion is due to concentrating many passengers' facilities in small zone, where various reverse movements are interfering. Moreover, the perpendicular collection for the entry and exit turnstiles creates more congestion. In summary, the large area of ticket hall is not enough for preventing the passenger congestion, as long as the distribution of service elements are not selecting in light of separating the reverse flow directions.

\subsection{Discussion}

Although accessibility can be easily achievable by improving the features of stations to remove basic barriers, the analysis showed that the examined stations do not fulfill the criteria for the accessibility of disables, where the major attention is directive to typical users only. Consequently, the requirements that need to be taken into account for all of third line stations are as the following:

- Minimizing the gap between the trains and platforms edges by using portable bridge plates or filler attached to the train cars [19].

- Providing at least one selling desk of the ticket office for use by passengers in wheelchair [5]; the top of desk should be at $0.76 \mathrm{~m}$ maximum above the floor, and height of knee recess of $0.700 \mathrm{~m}$ minimum above the floor.

- Adding an appropriate tactile warning surface directly in front of entries, along the walkway sand the platforms behind edges.

- Modifying of the sign design to include the necessary tactile information.

- Modifying the shape of the treads and risers of all stairs in addition to handrails to fulfill the requirements of passengers with disabilities. 


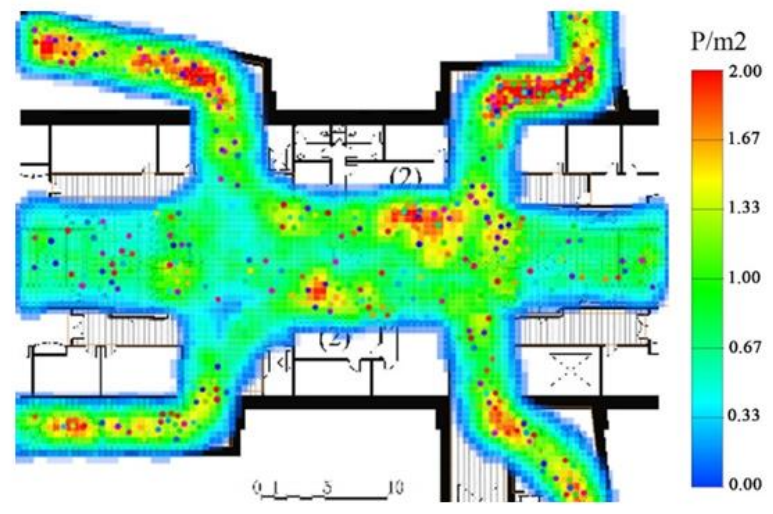

a. Tawfikia station

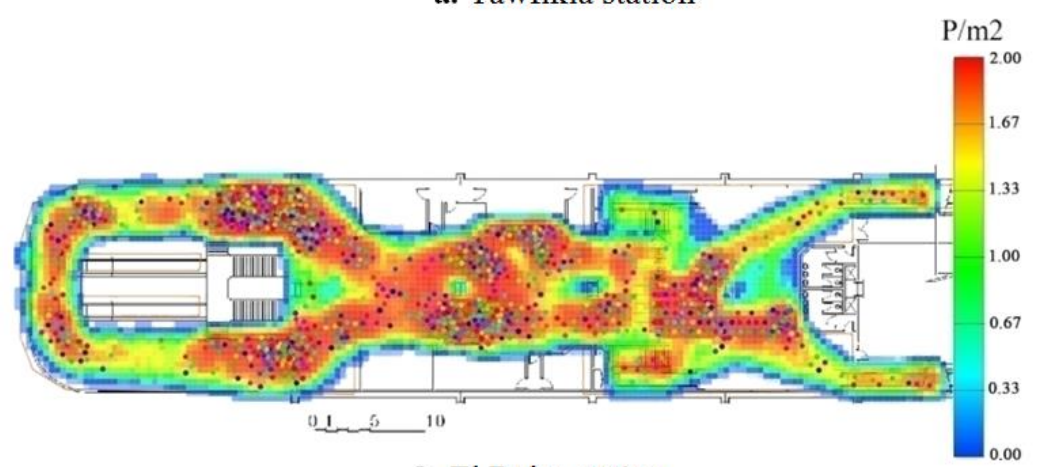

b. El Bohy station

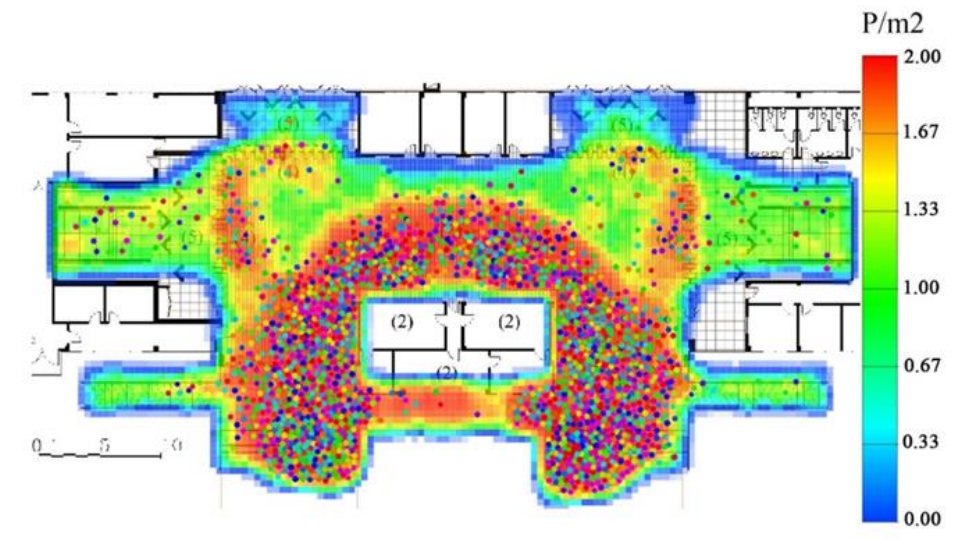

c. Rode El Farag

Fig. 6. Flow-density analysis in the ticket halls

Furthermore, flow-density evaluation showed that passengers in ticket halls of the examined stations will suffer from discomfort by varying ratios. Ticket hall of Tawfikia station, the less dense station, has the best level of passenger comfort, whereas the other two stations provide defective level of service. Bottlenecks resulted from the architectural arrangement of the ticket halls create uncomfortable flow conditions. Moreover, locating of the service facilities in crossflow creates congested movement zone. Additionally, the reverse movements of passengers through these zones increase the congestion problem. Therefore, applying the separation concept between the reverse movements in ticket hall, relocating the ticket office away from 
the passengers' movement as well as enlarging the right angel junction as much as possible will sufficiently enhance the passenger flow and provide passenger comfort accordingly.

\section{Proposals for flow density improvement}

To mitigate the congestion, simple modifications were proposed, and Any logic software was used to explore the efficiency of these proposals as the following.

\subsection{Tawfikia station}

As shown in Fig. 7(a), it is suggested to divide the ticket hall into two longitudinal zones, one exclusively for alighting passengers and the other for entering passengers. Accordingly, the two ticket offices are to be merged to one office in the entering zone. Queuing space in front of the new ticket office façade is also provided to hold the passenger queues.

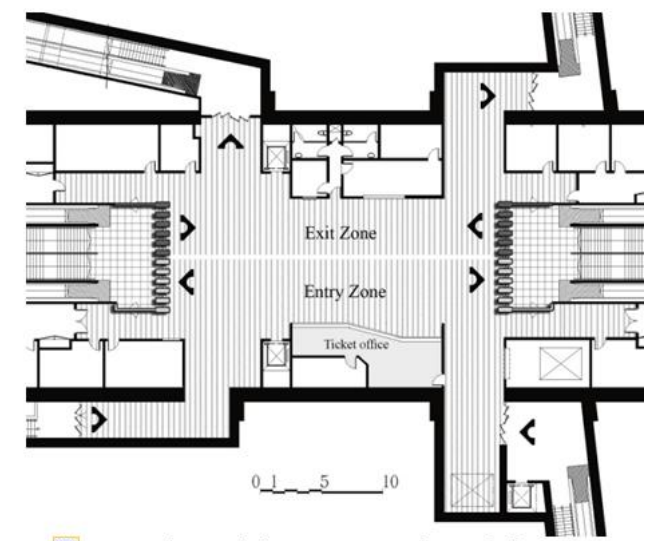

a. Plan of the proposed modifications

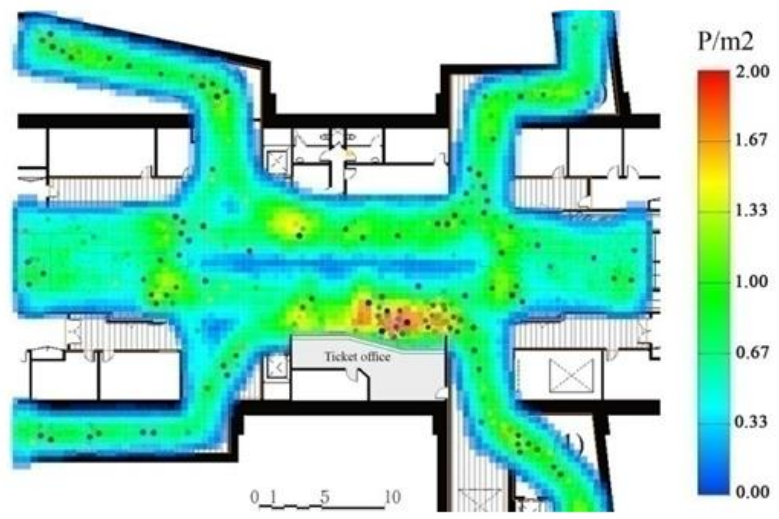

b. Distribution of passenger density

Fig. 7. Proposed treatment for Tawfikia station

As expected, flow-density has reduced and level of service has improved due to this proposal as shown in Fig.7(b). By comparing the result of the proposal with the result of the base case, it can obviously observe that the proposal yields the best performance although the capacities of all elements are constant in the two cases. The crowd movement zones in the entries disappeared, and the level of service has become grade D. while level of service in front of ticket office façade has also improved to grade $\mathrm{C}$. 


\subsection{El Bohy station}

Due to the limited width of the two ticket halls, the simplest modification to reduce the congestion is to appoint one ticket hall for exit of passengers and the other for entry. Additionally, ticket office in the entry hall needs to be shifted perpendicularly between the two entries to expand the free areas for passenger movements, as indicated on Fig. 8(a).The result of proposal analysis showed better performance than the base case, although the two cases have almost the same dimensions and volume of passengers.

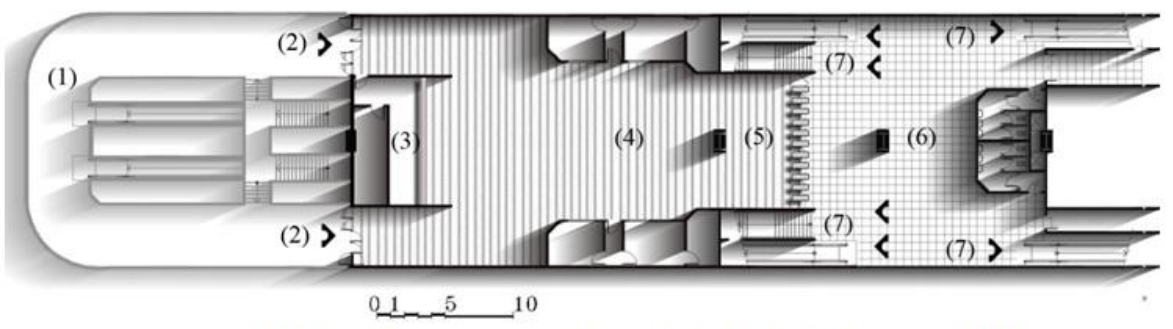

a. Plan of the proposed modifications in entry hall

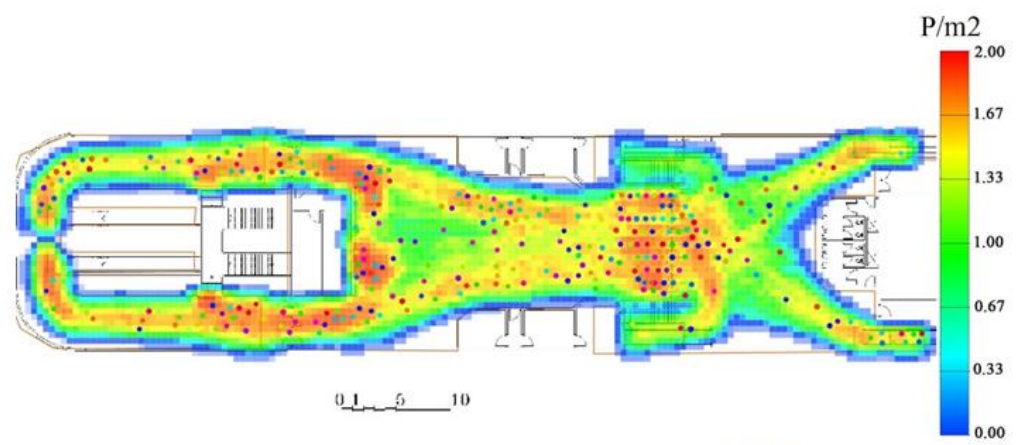

b. Passenger density in entry hall

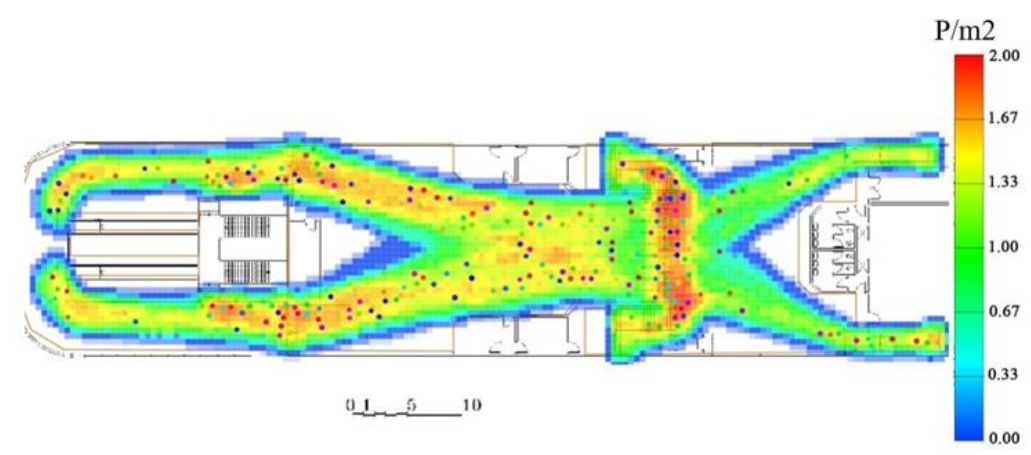

Fig. 8. Proposed treatment for Bohy station

As shown in Fig. 8 (b) \&(c), the congestion in different zones of both halls has efficiently reduced where level of service varied between grade C\&E. While level of service in front of ticket office façade has improved to grade C. By comparing the flow density in entry hall with flow density in exit hall, it can observe that the exit hall yields the best performance due to absence of any interfering activities with passenger movement unlike the entry hall that contains the ticket office. 


\subsection{Rode El Farag station}

The enhancing modifications include relocating the entry turnstiles and the ticket offices to be adjacent to each other, as shown in Fig. 9(a), in addition to adding of a new entrance for entering purpose only and the existing entries will be exclusively for exit. The new arrangement ensures the separating of reverse directions of flow and modifying the inappropriate collecting for turnstiles.

In the same context with other stations, the proposal has noticeably reduced the severe congestion as shown in Fig. 9(b). Shifting the ticket offices away from the entrances has improved the quality of service level at entries from grade $\mathrm{F}$ to D. Moreover, level of service in front of ticket office facades has improved from grade $\mathrm{D}$ to grade $\mathrm{C}$.

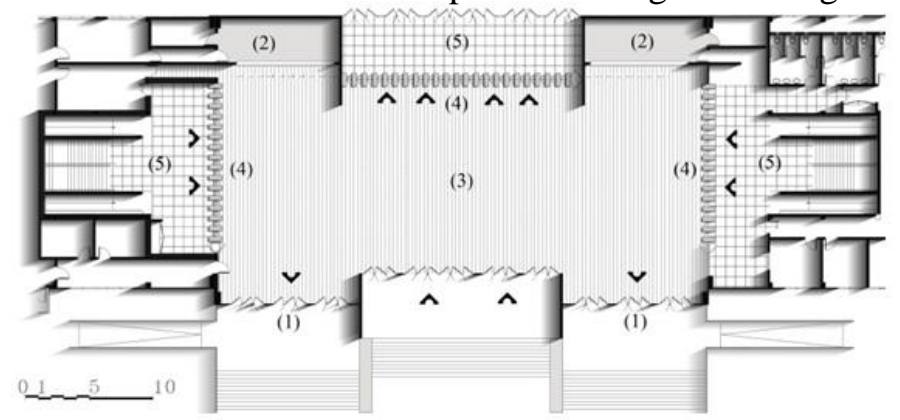

a. Plan of the proposed modifications

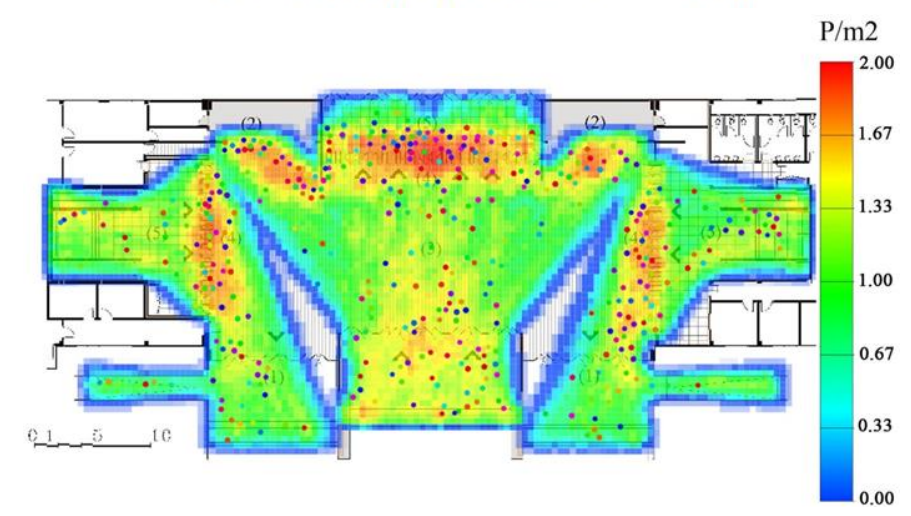

Fig. 9. Proposed treatment for Rode El Farag station

\section{Conclusions}

This work deals with the issues of equitable accessibility, and passenger comfort at micro-level of Cairo metro stations during normal conditions. The work evaluates and improves the accessibility of disables and the flow-density inside three future stations of the newest Cairo line as applied samples. The stations accessibility is evaluated based on an access check list extracted from Egyptian disability code and the ADA requirements, while the flow-density is analyzed using micro-simulation software. The results of accessibility evaluation clarified that some requirements are fulfilled (such as providing elevators and special access through turnstiles), and other major requirements are neglected. Therefore, all the stations will not be accessible for visually impaired passengers, whereas passengers with other types of disabilities will face difficulties in accessing the service. Furthermore, it was interestingly found that level of service during normal conditions will be poor and seriously 
uncomfortable, although the capacity of passenger facilities was standard calculated to ensure safe evacuation in emergency conditions. This result is justified due to the critical right angle junctions resulted from architectural configuration, positioning of some service facilities in cross-flow, and the reversed flow directions. These factors negatively affect the scenario of passengers flow and produce congested movement zones, which result in restricted walking speed, unavoidable contact with others, and unstable flow as the time elapsed, in addition to probable pushing and panic. To reduce the flow-density and to optimize passenger comfort accordingly, the separation between reverse movements of passengers boarding and alighting the station by separating the different facilities is very efficient concept. For ensuring that the future stations of Cairo metro network are designed to be comfortable, accessible and safe environment for all passengers, all accessibility requirements for passengers with disabilities should be taken into account. Moreover, the scenarios of passengers flow expected due to the internal arrangement should be explored using micro-simulation. Finally, the work results are of high interest for the architectural designers to realize and avoid these defects.

\section{REFERENCE}

[1] NFPA. "Standard for Fixed Guide way Transit and Passenger Rail Systems", USA : National Fire Protection Association, 2014.

[2] Sideris, A. S., Taylor, B. D. and Voulgaris, C. T.,"Passenger Flows in Underground Railway Stations and Platforms", USA : Mineta Transportation Institute, 2015.

[3]Voulgaris, C. T., Sideris, A. L. and Taylor, B. D., "Planning for Pedestrian Flows in Rail Rapid Transit Stations:Lessons from the State of Current Knowledge and Practice", 3, Journal of Public Transportation, Vol. 18, 2015.

[4] Egyptian Disability Code, Housing and Building National Research Center, 2007.

[5] ADA Standards, "Americans with Disabilities Act Standards", USA: U.S. Department Of Justice (DOJ), 2010.

[6]Hankin, B. D., and Wright, R. A., "Passenger Flow in Subways", 2, 10.2307/3006732, Vol. 9, pp. 81-88., 1958.

[7] Johansson, F., "microscopic modelling and simulation of pedestrian traffic", Linkoping university, Institute of technology, thesies no. 1629, Sweden, 2013.

[8] Fellendorf, M., and P. Vortisch., "Microscopic traffic flow simulator VISSIM. In Fundamentals of Traffic Simulation", 63-93. Springer, New York, 2010.

[9] Madkour, A., Hudson , M.A. and Bellaros, A., "Construction of Cairo Metro Line 2", no. 11668, P. 103-117, ,1999.

[10]Systra consulting group, "Greater Cairo Metro, AL Thawra Line (LINE 3) - Phase 3", Tender Document. Egypt : Ministry of transport, 2013.

[11] Shiwakoti, N., Shi,X., Ye, Z. and Wang, W., "Empirical study on pedestrian crowd behaviour in right angled junction", Sydney, Australia : s.n., Australasian Transport Research Forum, 2015.

[12] Galiza,R. J., Kim, I., Ferreira, L,. and Laufer, J.,"Modelling Pedestrian Circulation in Rail Transit Stations Using Micro-Simulation”, 32 ${ }^{\text {nd }}$ Australasian Transport Research Forum, 2011.

[13] Sahaleh, A., Bierlaire, M., Farooq, B., Danalet, A. and Hänseler, F. S.,"Scenario Analysis of Pedestrian Flow in Public Spaces", Switzerland : Ecole Polytechnique Fédérale de Lausanne (EPFL), 2012.

[14] Prasertsubpakij, D. and Nitivattananon, "Evaluating accessibility to Bangkok Metro Systems using multi-dimensional criteria", V. 2012, IATSS Research, Vol. 36, pp. 56-65.

[15] Fruin, J.J. "Pedestrian Planning and Design", s.l. : Metropolitan Association of Urban Designer and, 1971.

[16]VRIOG Steering Committee, "Railway Station Design Standard and Guidelines", Victoria : Victorian Rail Industry Operators' Group (VRIOG), 2011.

[17] Griffin, K. W., "Building Type Basics for Transit Facilities", John Wiley \& Sons, 2004.

[18] Binu, B., "Johansson "Design consideration for Rapid Rail Stations", Indian institute of technology roorkee, India, 2007.

[19]Levy, D.,'“Improving Accessibility at Metro. Los Angeles”, Metropolitan Transportation Authority, USA, 2013. 


\section{دراسة الوصول العادل و تدفق الركاب \\ في المحطات المستقبلية من شبكة مترو الوصن القاهرة}

$$
\text { الملخص العربى }
$$

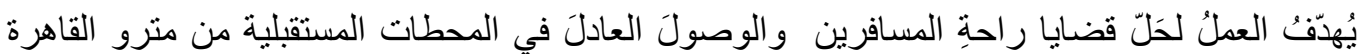

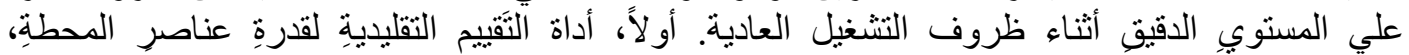

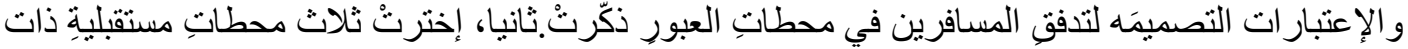

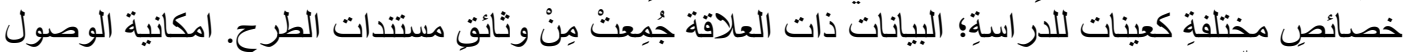

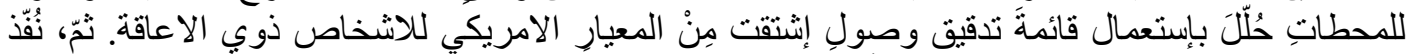

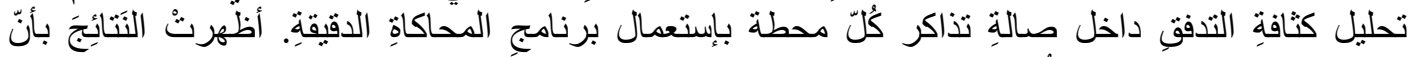

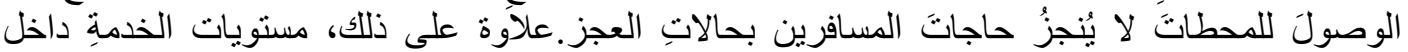

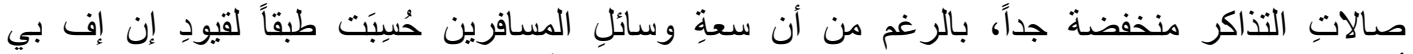

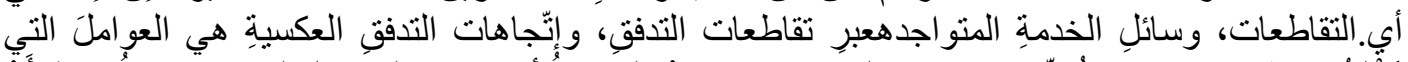

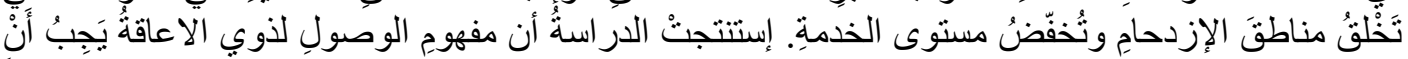

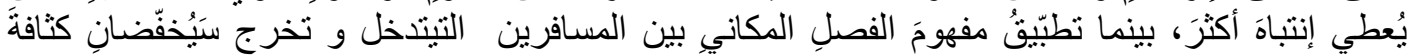

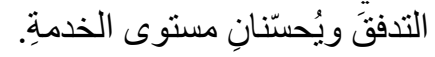

